\title{
DÉCADAS DE MICHELS: \\ MARCOS CONTEXTUAIS E PRAZO DE VALIDADE PARAA "LEI DE FERRO"
}

André Marenco

\author{
Maria Izabel Noll
}

\begin{abstract}
RESUMO
O argumento central deste artigo é que existe um prazo de validade temporal para o efeito da lei de ferro das oligarquias, proposição cunhada por Robert Michels em sua obra Sociologia dos partidos políticos, de 1911. O artigo esboça, na primeira seção, as bases sociais e institucionais que serviram como marcos contextuais propícios à conversão dos partidos socialistas europeus em princípios do século XX em oligarquias partidárias: a expansão do sufrágio e a integração na competição eleitoral de candidatos desprovidos de propriedades e renda, combinado a reformas eleitorais, com a substituição do voto majoritário pela representação proporcional, especialmente acompanhada pela transferência aos dirigentes da prerrogativa de confecção e classificação de listas de candidatos partidários. Na segunda seção, o artigo procura matizar os prognósticos sombrios de Robert Michels acerca da organização partidária, considerando os fatores que contribuem para maior ou menor delegação do poder interno dos partidos aos seus dirigentes.
\end{abstract}

PALAVRAS-CHAVE: Robert Michels; lei de ferro das oligarquias; democracia; partidos politicos; organização partidária.

\section{INTRODUÇÃO}

Conforme Popper (1963), a principal tarefa das Ciências Sociais consiste em identificar os efeitos não-intencionais provocados por ações humanas intencionais. Nesse ponto provavelmente reside a distinção entre os vários tipos de filosofia moral e a teoria positiva: enquanto para a primeira o mundo parece ser o produto de ações normativas que por meio de sanções e incentivos (constitucionais, morais) produz resultados congruentes às intenções originais, o desafio de explicar estruturas e processos políticos exige a compreensão dos efeitos perversos, produzidos pela interação de indivíduos dotados de intencionalidade, cujos resultados, longe de serem preditos por suas vontades originais, são refratados por oportunidades fixadas sob contextos institucionais,
"A democracia é, também ela, um tesouro que ninguém nunca poderá trazer à luz. Mas continuando as investigações e pesquisando incessantemente para encontrar o desconhecido, não deixaremos de realizar um trabalho útil e fecundo pela democracia" (MICHELS, 1982, p. 241).

históricos ou econômicos peculiares. Estabilidade política como resultado da combinação de formas corrompidas aristocracia-democracia de governo (Aristóteles); a ambição de um príncipe como motor para a construção dos modernos estados nacionais (Maquiavel); racionalidade individual como base para a obediência ao soberano (Hobbes); ambição como matéria-prima para a produção de equilíbrio e governo moderado (Madison); competição como mecanismo de responsabilização governamental (Schumpeter); no DNA dessa longa linhagem de teoria política poderemos encontrar uma percepção das conseqüências não previstas de ações individuais intencionais, como seu elemento genético nuclear.

Evidentemente, nesse panteão há um lugar especial para Michels. A "Lei de Ferro das

Rev. Sociol. Polít., Curitiba, v. 20, n. 44, p. 63-72, nov. 2012 
Oligarquias" está assentada sobre uma compreensão dos efeitos perversos presentes nas relações sociais. Ao alargar o sufrágio, e desejar a democracia, o resultado terminará sendo distinto ou oposto em relação às intenções originais: para compensar assimetrias sociais, será necessário erguer sólidas organizações partidárias, especialmente entre eleitores e ativistas despojados de recursos sociais e econômicos. Mas, lembra Michels, quem diz organização, diz oligarquia e, de meios projetados para estimular a participação, essas organizações terminam convertendo-se em novas oligarquias políticas. Perseguindo a democracia, terminamos por gerar mais concentração de poder na mão de poucos.

Não deixa de ser revelador comparar o conservador Michels com o revolucionário Gramsci quando a questão refere-se à oligarquização das organizações partidárias no início do século XX. Referindo-se diretamente à lei de ferro micheliana, Gramsci (1968) sugere que se deva distinguir democracia no Estado em relação a democracia nos partidos. Nestes, haveria uma necessidade de centralização decisória, como condição para a realização da democracia nas instituições estatais, espécie de versão de os fins justificam os meios. O mais importante, segue o ícone marxista do século passado, seria considerar se as distâncias chefes/seguidores remetem à fronteiras de classe: apenas em caso positivo faria sentido perder-se o sono por conta de uma delegação ascendente de poder; quando dirigentes e dirigidos pertencerem à mesma classe, esta divisão seria - para Gramsci - apenas técnica, remetendo metaforicamente às distâncias entre regente e músicos de uma orquestra. Quase um século mais tarde e várias nomenklaturas fora de moda, pode-se com segurança proferir a sentença de quem tinha razão, se os fins justificariam os meios, e divisões meramente técnicas seriam um preço modesto a pagar pela mudança social, ou, como profetizara Michels, "quem diz organização, diz oligarquia".

Este artigo pretende delimitar uma espécie de prazo de validade para o efeito da lei de ferro das oligarquias, cunhada por Michels. Nesta direção, esboça, na primeira seção, as bases sociais e institucionais que configuraram os marcos contextuais propícios à conversão nos emergentes partidos socialistas europeus em oligarquias partidárias: a expansão do sufrágio e a integração na competição eleitoral de candidatos desprovidos de propriedades e renda, combinado à reformas eleitorais, com a substituição do voto majoritário pela representação proporcional, especialmente acompanhada pela transferência aos dirigentes da prerrogativa de confecção e classificação de listas de candidatos partidários. Na segunda seção, este trabalho procura matizar os sombrios prognósticos de Michels acerca da organização partidária, considerando os fatores que contribuem para maior ou menor delegação aos dirigentes.

\section{BASES SOCIAIS E INSTITUCIONAIS DAS OLIGARQUIAS}

Traço comum às democracias representativas consiste no espaço ocupado pelos partidos como operadores da competição eleitoral. Semelhança que se encerra neste ponto, cedendo lugar a uma grande diversidade quanto ao formato e fisionomia partidários, padrões organizativos, longevidade, formas de ação, consistência das identidades políticas intrapartidárias, coesão e disciplina parlamentar, vínculos com os eleitores. Desafio presente na pauta da investigação política é o de se encontrar pistas capazes de explicar as variações observadas no fenômeno partidário. Regras eleitorais, motivações no voto e formas organizativas estão entre os componentes mais frequentes nesta pauta. Michels, juntamente com Ostrogorsky e Weber, estabeleceram as bases para uma abordagem organizacional no estudo dos partidos políticos. Nessa direção, a estrutura organizativa, o perfil e estratégias de quadros partidários oferecem um ângulo promissor para entender a dinâmica de cada partido. Sua configuração não se reduziria a epifenômeno de processos que se desenrolam além das fronteiras organizativas, a exemplo do voto, interpretado como produto de contingências legais e/ou macrosociais. Preferências e estratégias de quadros partidários, relações de poder entre lideranças, aspirantes a cargos e aderentes, e recursos disponíveis para fomentar lealdades eleitorais, parecem exercer um efeito ainda mais imediato sobre a configuração dos partidos.

No início do século XX, Max Weber (1984a; 1984b) deslocou o foco de sua observação para o interior dos partidos ${ }^{1}$, buscando captar mudanças

\footnotetext{
1 "Especialmente para o núcleo de elementos interesados en la existencia del partido, que elabora el programa en cada caso, elige la forma del procedimiento y designa los candidatos" (WEBER, 1984a, p. 1076-1077).
} 
no perfil dos indivíduos voltados à atividade política. A pista para explicar as metamorfoses na fisionomia partidária estaria na supremacia conquistada por profissionais - funcionários, nas organizações europeias, o boss, na política estadunidense - sobre notáveis, com o subsequente enquadramento dos parlamentares à disciplina partidária (WEBER, 1984a, p. 1085). Sugestiva a respeito é a descrição do cenário da Inglaterra até 1868: predominam honoratiores, como o pastor anglicano, professores e proprietários, entre os tories, o predicador e artesãos com oportunidade para firmar contatos sociais, nos whigs (ibidem). Para todos então, a política representava uma ocupação acessória, espécie de título honorífico válido para confirmar um prestígio social (idem, p. 1083). O incremento na competição leva ao aparecimento do election agent, que gradativamente amplia sua ascendência, empresariando votos e aliando-se à figuras como o demagogo plebiscitário, a exemplo de Gladstone (idem, p. 1086), e, mais tarde, com o whip. Transformando-se de clube de notáveis em máquina profissional, partidos adquirem centralização e densidade organizativa. É também o momento em que parlamentares são enquadrados na disciplina partidária, convertidos em bestas de votar ${ }^{2}$, na imagem anunciada por Weber, como resultado do domínio das máquinas partidárias. A expansão do sufrágio paradoxalmente vem acompanhada por a ascensão de representantes desprovidos de recursos sociais e econômicos, dedicados exclusivamente à política e dependendo dela para sua sobrevivência material: “[sem] d'autres qualifications dans la vie que celle de parlementaire, ils y tiennent. Car, en la perdent, ils pardraient tout"3 (TARDIEU, 1937, p. 33).

Quase à mesma época, Michels já havia dirigido sua atenção para as mutações que se manifestavam dentro dos partidos socialistas. A vocação destinada ao trabalho de ativar politicamente contingentes handicapés impunha a existência de

2 "Os parlamentares ingleses, com a exceção de alguns membros do Gabinete (e de alguns excêntricos) viram-se reduzidos à condição de bestas de votar, perfeitamente disciplinadas [...] o parlamentar nada tem mais a fazer senão votar e não trair o seu partido" (WEBER, 1984b).

3 “[Sem] outras qualificações na vida que a de parlamentar, eles mantinham-se nela [na vida política]. Pois, perdendo-a, eles perderiam tudo" (nota do revisor). uma rede organizativa, condição para compensar o desapossamento social de militantes dedicados às bandeiras partidárias (MICHELS, 1982, p. 27). Para assegurar órgãos de imprensa, responsáveis pelo proselitismo político, para garantir o sustento de indivíduos voltados integralmente à causa, desenvolvia-se um governo em miniatura, com pequenos empreendimentos comerciais e arrecadação financeira próprios (idem, p. 164). Adquirindo vida própria, movida em torno a uma complexa rede de interesses materiais, de prestígio e poder, a organização partidária inverte o fluxo da representação, tornando-se um fim em si. Os sintomas da oligarquização que toma conta da dinâmica partidária se apresentam no incremento da divisão e especialização do trabalho (idem, p. 65), maior verticalização e hierarquia (idem, p. 101) e, por fim, a estabilidade dos dirigentes em seus postos (idem, p. 61). É reveladora a comparação efetuada por Michels entre a perspectiva de mobilidade e segurança oferecidas pela organização partidária à antigos operários e condição semelhante, encontrada por filhos de camponeses na carreira eclesiástica ou militar (idem, p. 160).

A lei de ferro da oligarquia profetizada por Michels corresponde, assim, ao declínio dos notáveis, marcando a ascensão de um novo tipo de elite, formada pelos agentes partidários, que, detendo o controle de recursos como a seleção de candidatos, asseguram o oligopólio sobre a oferta política.

A fórmula básica da lei de ferro das oligarquias é singelamente clara: democracia exige organização - especialmente entre partidos apoiados por eleitores despojados de recursos econômicos e propriedade - e, com o tempo, organização converte-se em oligarquia. Contudo, as inferências causais indicadas por Michels para explicar o fenômeno da concentração de poder nas mãos de um círculo restrito de dirigentes partidários, termina por circunscrever-se a especulações de ordem psicológica ("necessidade de chefes", "gratidão", "necessidade de veneração", "inferioridade intelectual", "incompetência incurável") ou a uma suposta superioridade intelectual dos chefes, em contraposição a uma incompetência das maiorias. Neste ponto, devese perguntar sobre a validade universal desta le $i$, ou, inversamente a medida em que oligarquias partidárias surgem em condições temporalmente datadas e sob o molde de bases sociais e institucionais singulares. Séries temporais 
envolvendo a introdução de mecanismos de responsabilização governamental perante respectivos Parlamentos nacionais, adoção do sufrágio universal masculino e promoção de reformas eleitorais com a substituição de sistemas majoritários por fórmulas proporcionais, podem ser reveladoras acerca do contexto no qual a oligarquização partidária encontra terreno fértil para vir à luz. Uma apresentação dessas sequências, com informações adicionais sobre eleitorado, filiação e votos socialistas, pode ser encontrada na Tabela 1, abaixo.

TABELA 1 - DADOS PARTIDÁRIO-ELEITORAIS DE PAÍSES EUROPEUS SELECIONADOS

\begin{tabular}{|c|c|c|c|c|c|c|c|c|}
\hline PAÍS & $\begin{array}{c}\text { GO- } \\
\text { VERNO } \\
\text { RES- } \\
\text { PON- } \\
\text { SÁVEL }\end{array}$ & $\begin{array}{c}\text { \% EM- } \\
\text { FRAN- } \\
\text { CHISE- } \\
\text { MENT } \\
\text { ÚLTIMA } \\
\text { ELEIÇÃO } \\
\text { ANTES } \\
\text { SUFRÁ- } \\
\text { GIO }\end{array}$ & $\begin{array}{l}\text { ANO } \\
\text { SU- } \\
\text { FRÁ- } \\
\text { GIO } \\
\text { MAS- } \\
\text { CULI- } \\
\text { NO }\end{array}$ & $\begin{array}{l}\text { PAR- } \\
\text { TIDO } \\
\text { SO- } \\
\text { CIA- } \\
\text { LISTA }\end{array}$ & $\begin{array}{c}\text { FILIA- } \\
\text { ÇÃO } \\
\text { PAR- } \\
\text { TIDOS } \\
\text { SO- } \\
\text { CIA- } \\
\text { LISTAS } \\
\text { (1910) }\end{array}$ & $\begin{array}{c}\text { ENGA- } \\
\text { JÁ- } \\
\text { MENTO } \\
\text { (FIL/ } \\
\text { ELEI- } \\
\text { TO- } \\
\text { RES) }\end{array}$ & $\begin{array}{l}\% \text { VOTOS } \\
\text { SOCIA- } \\
\text { LISTAS } \\
(1900- \\
1920)\end{array}$ & $\begin{array}{c}\text { ANO } \\
\text { REFORMA } \\
\text { RP/LF }\end{array}$ \\
\hline Alemanha & 1918 & 36 & 1871 & 1875 & 4,8 & 0.15 & 31,0 & 1919 \\
\hline Áustria & 1818 & 13 & 1907 & 1889 & 7,6 & 0.25 & 30,8 & 1918 \\
\hline Bélgica & 1831 & 4 & 1893 & 1885 & & 0.14 & 29,3 & 1899 \\
\hline Dinamarca & 1901 & 27 & 1848 & 1876 & 8,7 & 0.32 & 27,3 & 1920 \\
\hline Finlândia & 1919 & & 1907 & 1899 & 4,2 & 0.10 & 40,9 & $1906 * V P$ \\
\hline França & 1875 & 44 & 1848 & 1905 & 0,8 & 0.05 & 14,1 & 1919 \\
\hline Irlanda & - & 78 & 1918 & 1922 & & & & $1922 * V P$ \\
\hline Itália & 1852 & 16 & 1913 & 1892 & 0,6 & 0.02 & 22,0 & $1919 * V P$ \\
\hline Holanda & 1848 & 11 & 1918 & 1894 & 2,3 & 0.15 & 15,0 & $1918^{*} \mathrm{VP}$ \\
\hline Noruega & 1885 & 12 & 1900 & 1887 & 6,2 & 0.27 & 22,8 & 1921 \\
\hline Suécia & 1917 & 10 & 1911 & 1889 & 7,8 & 0.34 & 22,9 & 1909 \\
\hline Reino Unido & 1800 & 28 & 1918 & 1900 & & & 9,9 & \\
\hline
\end{tabular}

FONTES: os autores, a partir de Przeworski (1986), Katz e Mair (1994), Bartolini (2000) e Colomer (2004).

O laboratório adotado por Michels para a observação das tendências oligárquicas na organização de partidos socialistas foi o Partido SocialDemocrata Alemão (SPD). Esse partido foi precocemente fundado em relação aos demais partidos socialistas europeus, praticamente simultâneo à igualmente prematura franquia ao voto masculino, que representava até então pouco mais de 1/3 do eleitorado. Em pouco mais de três décadas, ele incorporou sob sua organização cerca de $4,8 \%$ do eleitorado alemão, alcançando uma votação média de $31 \%$ nas duas primeiras décadas do século XX. O estabelecimento tardio (1918) de dispositivos de responsabilização formal do gabinete de governo perante o parlamento e uma reforma eleitoral na direção da substituição de eleição majoritária em distritos uninominais criado em 1871 por fórmula proporcional com listas fechadas (1919) completaram a configuração institucional gerada nesse momento.

Nos partidos de notáveis do século XIX, a assimetria entre representantes e representados, dirigentes e membros partidários fora, paradoxalmente, residual (GAXIE, 1989, p. 14; BEST \& COTTA, 2000; BEST \& GAXIE, 2000). Em eleitorados censitários, representantes eram primus inter pares, indivíduos cuja reputação familiar, diploma, propriedades não chegavam a fixar distâncias significativas em relação a seus eleitores. Da mesma forma, as reduzidas dimensões do eleitorado e as semelhanças sociais e ideológicas entre eventuais competidores não forneceram incentivos para a formação de máquinas eleitorais, voltadas à geração de finanças, conquista de votos e redução no custo da informação, através de ideologias e rótulos partidários. Representantes possuíam fortuna familiar, diplomas, reputação e relações sociais, como matéria prima para o voto. A confiança, traduzida em sufrágios, podia ser obtida através da reputação pessoal, alimentada em vínculos de lealdade, amizade e deferência interindividuais ${ }^{4}$. Por isso, as rarefeitas estruturas 
organizacionais das facções políticas censitárias do século XIX não comportavam espaço para relações socialmente assimétricas entre representantes, dirigentes, membros e eleitores, que se assemelhavam em termos de capitais social e econômico.

O alargamento do sufrágio mudou tal cenário, com o aparecimento de um novo tipo de candidato, que não tinha à sua disposição fortuna pessoal, reputação individual ou recursos de patronagem (WEBER, 1984b). Suas melhores expressões foram os quadros saídos das classes médias que ingressaram no radicalismo, na França da III República (BIRNBAUN, 1980, p. 30; GAXIE, p. 47) ou, principalmente, do mundo sindical, a exemplo da social-democracia alemã. "On peut donc caracteriser le nouveau personnel politique comme un ensamble d'individus qui proviennent de manière prédominant des professions libérales et de la petite fonction publique, voués entièrement à l'exercice de leur tâche politique partisanne et bénéficient d'un grande stabilité. Grâce à des réélections sucessives dans une même arrondissement, dont ils sont presque toujours originaires et dans lequel ils ont commencé par occuper, avant mêmes d'être élus deputés, des fonctions électives locaux"5 (BIRNBAUN, 1980, p. 40).

Como condição para desafiar notáveis que monopolizavam as cadeiras legislativas, candidatos de origem social mais baixa, precisam compensar a escassez de recursos pessoais - notoriedade, diploma, posses - pela disponibilidade de militância voluntária, finanças coletivas e rótulos ideológicos como programas, visões de mundo, valores éticos, bandeiras sociais, transferidos pela identificação partidária. Como destaca Offerlé, a relevância de

\footnotetext{
4 “O deputado detinha o monopólio dos empregos e, de modo geral todas as espécies de monopólio relativas aos negócios de sua circunscrição. E, de sua parte, agia com muita cautela nas relações com os homens de prestígio local, a fim de assegurar reeleição" (WEBER, 1984a, p. 88)

5 "Pode-se então caracterizar o novo pessoal político como um conjunto de indivíduos que provinham de maneira predominante das profissões liberais e da pequena burocracia pública, dedicados inteiramente ao exercício de sua tarefa política partidária e beneficiando-se de uma grande estabilidade. Graças a reeleições sucessivas em um mesmo distrito, de que eles são quase sempre originários e no qual eles começaram a ocupar funções eletivas locais, mesmo antes de serem eleitos deputados" (N. R.).
}

identificação partidária na produção de candidaturas cresce paralelo à expansão do mercado eleitoral: "étudier a la fin du XIXème siècle en un millieu urbain, c'est souligner comment l'on passe d'un repertoire de mobilization d'abbord fondé sur l'offre de biens privés, à un offre de biens plus abstraits - des biens publics indivisibles - office de discours, de répresentations, d'images de l'avenir, de politiques immateriales"" (OFFERLÉ, 1989, p. 167).

O progressivo enfranchisement eleitoral, seguido pela ascensão de partidos socialistas termina por tornar disfuncionais os diferentes procedimentos de voto majoritário, até então exclusivos como mecanismo de conversão de sufrágios em cadeiras parlamentares. Em seu lugar, são introduzidas mudanças baseadas em fórmula proporcional, acompanhada na maioria dos casos por procedimentos de ordenamento prévio de candidatos partidários, conhecidos como listas fechadas: assim, apenas quatro anos separam na Bélgica a adoção de sufrágio universal masculino (1885) e a reforma para representação proporcional com listas fechadas (1889). Na Suécia, foram necessários 20 anos entre o alargamento do sufrágio (1889) e o voto em listas partidárias proporcionais (1909). Um pouco mais tardias foram as mudanças de regras eleitorais em direção ao voto proporcional com listas pré-ordenadas na Áustria (1918), Alemanha (1919), França (1919), Dinamarca (1920) e Noruega (1921). Paralelamente, Finlândia (1906), Holanda (1918), Itália (1919) e Irlanda (1922) também substituem o voto majoritário por fórmula proporcional, variando, entretanto, no que diz respeito ao procedimento de alocação das cadeiras partidárias entre seus candidatos. Nesse contexto, o Reino Unido permaneceu como exceção, ao preservar seu modelo de first-past-the-post em distritos uninominais.

Analisando processos de mudança nas instituições eleitorais, Boix (1999) infere que a alteração de fórmula majoritária para representação

\footnotetext{
6 "Estudar o fim do século XIX em um ambiente urbano é sublinhar como se passa de um repertório de mobilização inicialmente fundado sobre a oferta de bens privados a [um fundado sobre] oferta de bens mais abstratos - bens públicos indivisíveis -: possibilidades de discursos, de representações, de imagens do futuro, de políticas imateriais" (N. R.).
} 
proporcional teria sido resultado de estratégias de elites políticas face à (a) ascensão eleitoral de partidos socialistas, combinado ao (b) equilíbrio e incapacidade de resolução de problemas de coordenação por partidos tradicionais. Em outras palavras, partidos socialistas ascendentes, partidos tradicionais de notáveis competindo pelos mesmos votos e fórmula majoritária, prenunciariam governos socialistas com maioria parlamentar, e, dessa forma, distribuição proporcional dos assentos legislativos ofereceria possibilidade de conter os efeitos mecânicos da regra majoritária, com o desperdício de votos minoritários dispersos entre os partidos tradicionais, que poderiam recompor e coordenar sua ação em um cenário pós-eleitoral, no interior das casas parlamentares.

Mais complexa parece ser a busca de uma explicação para a preferência adotada por procedimentos de alocação de vagas partidárias baseados em listas fechadas e pré-ordenadas, que parecem ser uma criação típica deste período. Registros de reformas eleitorais entre os séculos XIX e XXI (COLOMER, 2004; MARENCO, 2006) revelam que aproximadamente $50 \%$ de todas as mudanças com adoção de voto proporcional combinado a listas fechadas foram promovidas nessas décadas de Michels, até 1930.

Aqui, o testemunho de Michels (1982, p. 238) pode apresentar um insight persuasivo: "A organização é a fonte de onde nasce a dominação dos eleitos sobre os eleitores, dos mandatários sobre os mandantes, dos delegados sobre os que delegam. Quem diz organização, diz oligarquia". Se o alargamento do sufrágio introduziu na competição um novo tipo de eleitor e de candidatos - desprovidos de propriedades, status e recursos materiais - e se a organização e a conversão dos partidos socialistas em máquinas de fabricar ativistas, finanças e proselitismo estavam em estado avançado de consolidação institucional nas duas primeiras décadas do século passado, conforme o registro de Michels para o SPD alemão, seria de esperar-se uma escolha por procedimentos que transferissem prerrogativas de nominação de candidatos parlamentares aos líderes partidários. Ao contrário do que advoga modelo convencional de engenharia eleitoral, para o qual listas pré-ordenadas teriam constituído incentivo institucional a induzir a formatação de organizações partidárias estáveis e disciplinadas, podemos extrair do relato de Robert Michels uma outra ordem dos fatores na qual reformas eleitorais para listas proporcionais pré-ordenadas foram resultado da constituição prévia de poderosas oligarquias partidárias.

Observando-se o percentual de filiados a partidos socialistas em relação ao eleitorado nacional respectivo, em torno a 1910, verifica-se o quão robustas já eram estas organizações antes das mudanças nas regras eleitorais: $4,8 \%$ na Alemanha, $7,6 \%$ na Áustria, $7,8 \%$ na Suécia, $8,7 \%$ na Dinamarca. Os partidos socialistas franceses $(0,8 \%)$ e italianos $(0,6 \%)$ apresentam estruturas mais rarefeitas e diminutas. Considerando apenas a densidade organizacional, definida pela relação entre filiados/votos socialistas, pode-se verificar uma escala que passa por $15 \%$ na Alemanha, até 34\% na Suécia. Parece revelador destacar que o SPD, embora representasse 31\% dos votos, uma das mais elevadas proporções entre os socialistas europeus, possuía relação mais modesta entre filiados/eleitorado e mesmo filiados/ votos socialistas. Em outras palavras, isto parece indicar crescimento eleitoral, de um lado, maior concentração da estrutura partidária, de outro.

O surgimento do sistema proporcional e o mecanismo de lista fechada, contribuem para reforçar lealdades partidárias, ao mesmo tempo em que consagram a impessoalidade dos mandatos parlamentares. Embora as razões que motivaram sua adoção tenham variado em cada caso - o medo dos conservadores quanto ao crescimento e eventual obtenção da maioria pelos socialistas, ou o a pretensão destes em assegurar representação - o resultado é que, sob esse formato eleitoral, e, ainda, submetido às condições de lista partidária fechada, o eleitor viu-se frente à uma opção impessoal e o candidato, submetido ao controle exercido pela organização partidária que, afinal, passa a definir quem pode ser candidato e sua posição na lista.

\section{QUEM DIZ OLIGARQUIA DIZ COMPE- TIÇÃO?}

O ponto vulnerável do diagnóstico traçado por Michels parece residir na unilateralidade que confere às relações entre chefes, aderentes e eleitores. Em contraste à superioridade nata dos líderes, suas bases seriam formalmente incompetentes, propensas à veneração e dependentes psicologicamente de seus chefes (MICHELS, 1982, p. 53-57). Michels não 
identifica, assim, a ocorrência de algum condicionamento exercido por aderentes e eleitores, reduzindo o domínio dos dirigentes a uma relação de soma-zero. Mais apropriado talvez fosse considera-la como uma reciprocidade assimétrica (PANEBIANCO, 1990: 64), que, sem desprezar o predomínio dos dirigentes, a percebe como fundada em um intercâmbio desigual, uma relação onde a lealdade precisa ser conquistada, frente ao risco potencial de evasão. Da mesma forma, para Mair (1997), as pistas capazes de fornecer uma explicação para a dinâmica partidária deveriam ser procuradas menos em alinhamentos políticos ou na "crise de ideologias", mas, sobretudo, em sua dimensão organizacional. Três variáveis permitiriam, de acordo com Mair a compreensão de seus efeitos sobre a configuração partidária: as características da liderança partidária, a natureza dos apelos formulados pelos partidos e a estratégia organizacional adotada por cada legenda ${ }^{7}$.

Sob quais circunstâncias, loyalty sobrepõe-se a exit como orientação para o comportamento de militantes partidários? Quais as coordenadas que permitem a compreensão de vínculos de lealdade entre dirigentes e bases partidárias, como aqueles descritos por Michels? Pista inicial para responder à esta questão pode ser localizada nos insights indicados por Hirschman: seletividade para o ingresso, processos de iniciação severa e elevados custos para a defecção seriam responsáveis por uma matriz de preferências nas quais loyalty $>$ voice > exit (HIRSCHMAN, 1970, p. 93).

Maior desequilíbrio nos vínculos verticais entre dirigentes/membros/eleitores tende a ocorrer quando incentivos não podem ser obtidos em outra organização, resultando em maior deferência e credibilidade da direção partidária (PANEBIANCO, 1990, p.79). Isto acontece, com maior frequência, quando distâncias ideológicas são percebidas pelos eleitores como suficientemente largas para inibir a opção de migrar para outras alternativas, ou ainda se o acesso aos recursos distribuídos pelo partido obedecer a um fluxo único e hierárquico.

\footnotetext{
7 Exemplo disso pode ser verificado no trabalho de Bacot (1979), sugerindo uma relação entre mudanças intergeracionais nos quadros dirigentes dos socialistas franceses e alterações em suas estratégias políticas e formas de organização a partir dos anos 1970.
}

A natureza das relações entre dirigentes e aderentes partidários e os mecanismos de lealdade produzidos em seu interior, ofereceriam, conforme Panebianco, a chave para desvendar a configuração dos partidos políticos. Um quadro de estabilidade organizativa resultaria, nesta perspectiva, do êxito do núcleo de interessados em controlar e mobilizar quando necessário mecanismos próprios de remuneração política. Podem apresentar-se como incentivos coletivos - a identidade compartilhada - ou seletivos, estes, presentes no status pela posição ou responsabilidade assumidos, ou em recompensas materiais (idem, p. 67). Nos partidos de massa, a capacidade da organização preencher a vida social de seus membros - que a precariedade material e espiritual de sua existência privada muitas vezes não lhes permite - constitui, ainda, uma forma de remuneração que cimenta lealdades: oferecendo alternativas de lazer, círculos de amizade, solidariedade, assistência e, inclusive, uma espécie de micromercado matrimonial, o partido converte-se em uma community of fate (idem, p.79) ${ }^{8}$, que dissolve fronteiras entre indivíduo e coletivo. A importância destas formas diversificadas de aderência, capazes de integrar toda a heterogeneidade de seus membros pode ser melhor percebida quando se constata a relação entre o declínio do ativismo partidário e o

8 Ou ainda, na descrição de Gaxie: "la camaraderie, les plaisirs des 'collages', des 'ventes' et des 'porte à porte', la solidarité, la cohesion, la communauté de goûts et de sentiments, l'identification à un groupe, les joies de la victoire, les reconfourts mutuels dans la défaite ou dans les malheurs individuels, les risques et les épreuves affrontés en commun, les réunions où se retrouvent les vieux amis et où s'égrainent les souvenirs, les controverses passionnés, les longues discussions poursuivies au café, l'affection, la complicité, l'amitié des militants procurent des joies que l'on peut juger prosaïques ou accessoires, mais qui constituent pourtant un puissant moyen d'attachement au parti" (GAXIE, 1977, p. 137) ["A camaradagem, os prazeres das 'colagens', das 'vendas' e dos 'de porta em porta', a solidariedade, a coesão, a comunidade de gostos e de sentimentos, a identificação com um grupo, as alegrias da vitória, os reconfortos mútuos na derrota ou nas infelicidades individuais, os riscos e as provas combatidos em comum, as reuniões em que se encontram os velhos amigos e em que se compartilham as lembranças, as controvérsias apaixonadas, as longas discussões realizadas no café, o afeto, a cumplicidade, a amizade dos militantes obtendo as alegrias que se pode considerar prosaicas ou acessórias, mas que entretanto constituem um poderoso meio de vínculo ao partido" - N. R.]. 
encolhimento de estruturas capilares de arregimentação ${ }^{9}$.

A oportunidade para maior coesão partidária estaria associada ainda ao seu padrão fundacional. Quando a organização expande-se por penetração, a partir de e espelhando-se em seu núcleo partidário original, seriam maiores as probabilidades para a afirmação de identidades ao centro. Inversamente, crescendo por difusão, por meio da integração de elites locais ou regionais em uma estrutura federativa, a organização estaria mais propensa à flexibilidade e a à necessidade de negociações para a geração de consensos mínimos ${ }^{10}$, como observado entre os partidos estadunidenses. Interfere, igualmente, a natureza interna ou externa (Igreja, sindicatos, Estado) das fontes que emprestam sua legitimidade à organização (idem, p. 132), afetando as chances de domínio do núcleo dirigente e o tipo de relações que estabelece com seus seguidores.

A natureza predominante dos incentivos (coletivos-seletivos) e o controle sobre sua distribuição (concentrado-disperso) delineariam os contornos de cada organização partidária. Coesão e homogeneidade organizativas seriam conformadas pelas relações entre dirigentes e agrupamentos intra-partidários e a capacidade dos dirigentes em administrar áreas de incerteza (idem, p. 65), pontos críticos que, ao serem controlados, forneceriam os meios para a construção de identidades partidárias consistentes: atributos coletivamente valorizados, reconhecidos nos quadros dirigentes; relações com a periferia

\footnotetext{
9 Confirmado pela observação de Seyd e Whiteley (1996) sobre o declínio nas formas de mobilização de aderentes pelos partidos Trabalhista e Conservador, na Inglaterra, relacionado ao "developpement de formes alternatives de loisirs ou de modalités nouvelles d'action politique [...] les partis eux- mêmes contribuent à ce processus en réduissant les opportunités d'adherer ou de participer à la activité du mouvement" ["desenvolvimento de modos alternativos de prazeres ou de modalidades novas de ação política [...] os próprios partidos contribuem para esse processo ao reduzirem as oportunidades de aderir ou de participar da atividade do movimento" - N. R.]

$10 \mathrm{O}$ que difere da classificação formulada por Duverger de partidos de criação interna ou externa. Como lembra Panebianco, os partidos Liberal e Conservador, na Inglaterra, seriam, conforme a tipologia de Duverger, partidos internos. No entanto, diferem por sua construção, respectivamente por difusão e penetração (PANEBIANCO, 1990, p. 110).
}

partidária; controle sobre o fluxo de informações internas; e, mecanismos de recrutamento e seleção de candidatos a postos políticos (idem, p. 88). Como ilustração, pode-se considerar a observação de Tsebelis identificando no poder de veto dos órgãos dirigentes centrais o traço distintivo dos partidos ingleses, com relação aos EUA: "semelhante alteração [a supressão desse poder de veto] teria significado a americanização do Partido Trabalhista, no sentido de que deixaria de existir uma autoridade central no partido. O GMC de cada distrito estaria apto a indicar os candidatos de sua escolha sem enfrentar qualquer obstáculo e, a longo prazo, o grupo parlamentar comporse-ia de MPs ${ }^{11}$ sem quaisquer vínculos comuns, mas que refletiriam fielmente o GMC de seus distritos" (TSEBELIS, 1998, p. 149).

Nessa direção, convém não extrapolar o prazo de validade da lei de ferro micheliana: ela parece referir ao contexto classificado por Katz e Mair (1994) como o do predomínio dos partidos de massa, e está baseada em um tripé (a) ativismo voluntário, (b) finanças coletivas e, (c) ideologias partidárias como vantagens comparativas na competição eleitoral e sua disponibilidade oligopólica por dirigentes partidários. A era dos cartel-parties implica em forte desvalorização de organizações partidárias robustas como diferencial na competição por votos: o financiamento eleitoral vem, agora, de subsídios estatais, não necessitando mais das cotizações extensivas de grande número de filiados; meios de comunicação e marketing profissional substituem o ativismo voluntário como recurso de proselitismo eleitoral; ideologias partidárias dão lugar à avaliação retrospectiva do desempenho governamental. As distâncias entre representantes e representados podem não ter se encurtado, mas não estão mais baseadas em recursos endógenos às organizações partidárias.

\section{FECHO}

A estabilidade e a consistência das organizações partidárias estariam associadas à sua capacidade em assegurar uma condição de oligopólio sobre a oferta da representação política. $\mathrm{O}$ fornecimento de identidades não recambiáveis, para eleitores, e oportunidades de acesso a postos, para aspirantes

11 GMC: General Management Council (Conselho Diretor Geral, em inglês); MP: membro do parlamento (isto é, parlamentar) (N. R.). 
à carreiras políticas constituem os assets que permitem à sua liderança a imposição de lealdades e relações hierárquicas.

Para Wanderley Guilherme dos Santos (1985), a predição de Michels sobre a inevitabilidade na conversão de organizações partidárias em oligarquias estaria temporalmente delimitada a um contexto no qual partidos detiveram o monopólio da representação política. A emergência de organizações societárias rivalizando com os partidos a prerrogativa de expressar as preferências dos cidadãos terminaria por quebrar seu oligopólio e, por consequência, as bases responsáveis por constituir as assimetrias entre representantes e representados sobre as quais está assentada a lei de ferro micheliana. Embora a expectativa de que a arte da associação pudesse rivalizar - e eventualmente substituir - as organizações partidárias não possua comprovação efetiva, o argumento parece indicar a competição, como espécie de kriptonita para as oligarquias partidárias.

De Madison a Schumpeter, uma larga tradição na teoria política identifica nas conseqüências não previstas da ação de agentes estrategicamente orientados pela maximização de interesses exclusivos, as condições mais prováveis para a própria contenção do poder e prerrogativas destes agentes. A ambição freia a ambição, anota Madison. A competição pela liderança politica configura procedimento diferencial dos regimes democráticos, pondera Schumpeter. A suposição implícita aqui é que a competição política em condições de equilíbrio e incerteza provoca dispersão de recursos estratégicos e redução nas assimetrias entre dirigentes e seguidores, ou, ao menos, maiores responsividade e potencial de responsabilização de representantes por seus representados. Sob coordenadas de (i) incremento na competição eleitoral, (ii) mudanças sociais e demográficas - com mobilidade social e escolarização em maiores escalas - e (iii) deslocamento na oferta de capital eleitoral para fora dos partidos (subvenções estatais, profissionalização de campanhas eleitorais e voto retrospectivo), até que ponto a lei de ferro das oligarquias não teria ultrapassado seu prazo de validade?

André Marenco (amarenco@terra.com.br) é Doutor em Ciência Política pela Universidade Federal do Rio Grande do Sul (Ufrgs) e professor do Programa de Pós-Graduação em Ciência Política da mesma instituição.

Maria Izabel Noll (minoll@terra.com.br) é doutora em Ciência Politica pela École des Hautes Études en Sciences Sociales (França) e Professora do Programa de Pós-Graduação em Ciência Política da Universidade Federal do Rio Grande do Sul (Ufrgs).

\section{REFERÊNCIAS BIBLIOGRÁFICAS}

BACOT, P. 1979. Les dirigeants du parti socialiste. Histoire et sociologie. Lyon: Presses Universitaires de Lyon.

BARTOLINI, S. 2000. The Political Mobilization of the European Left, 1860-1980: The Class Cleavage. Cambridge (UK): Cambridge University.

BEST, H. \& COTTA, M. (eds.) 2000. Parliamentary Representatives in Europe 18482000. Legislative Recruitment and Careers in Eleven European Countries. London: Oxford University.

BEST, H. \& GAXIE, D. 2000. Detours to Modernity: Long-Term Trends of Parliamentary Recruitment in Republican
France 1848-1999. In: BEST, H. \& COTTA, M. (eds.). Parliamentary Representatives in Europe 1848-2000. Legislative Recruitment and Careers in Eleven European Countries. London: Oxford University.

BIRNBAUN, P. 1977. Les sommets de l'Etat. Essai sur l'elite du pouvoir en France. Paris: Seuil.

(ed). 1985. Les Élites socialistes au pouvoir, 1981-1985. Paris: PUF.

BOIX, C.1999. Setting the Rules of the Game: The Choice of Electoral Systems in Advanced Democracies. American Political Science Review, Washington (DC), v. 93, n. 3, p. 609624, Sept. 
COLOMER, J. 2003. Handbook of Electoral System Choice. New York: Palgrave-Macmillan.

DUVERGER, M. 1983. Os partidos políticos. Brasília: UNB.

GAXIE，D. 1977. Economie des partis et rétributions du militantisme. Revue Française de Science Politique, Paris, v. 27, n. 1, p. 123154. Disponível em: http://www.persee.fr/ web/revues/home/prescript/article/rfsp_00352950_1977_num_27_1_393715. Acesso em : 15.out. $201 \overline{2}$.

1989. Explication du vote: un bilan des études électorales en France. Paris: Fondaction Nationale de Science Politique.

GRAMSCI, A. 1968. Robert Michels e os partidos políticos. In: Maquiavel, a política e o Estado moderno. Rio de Janeiro: Civilização Brasileira.

HIRSCHMAN, A. 1977. Salida, voz y lealtad. Ciudad de Mexico: Fondo de Cultura Económica.

KATZ, R. \& MAIR, P. 1994. How Parties Organize. London: Sage

MAIR, P. 1997. Party System Change. Approaches and Interpretations. London: Oxford University.

MARENCO, A. 2006. Regras eleitorais importam? Modelos de listas eleitorais e seus efeitos sobre a competição partidária e o desempenho institucional. Dados, Rio de Janeiro, v. 49, n. 4, p. 721-749. Disponível em: http:// www.scielo.br/pdf/dados/v49n4/03.pdf. Acesso em: 15.out.2012.

MICHELS, R. 1982. Sociologia dos partidos políticos. Brasília: UNB.

OFFERLÉ, M. 1989. Mobilization électorale et invenction du citoyen: l'exemple du milieu urbain français à la fin du XIX siécle. In: GAXIE, D. (ed.). Explication du vote: un bilan des études électorales en France. Paris: Fondaction Nationale de Science Politique.

PANEBIANCO, A. 1990. Modelos de partidos. Organización y poder en los partidos políticos. Madrid: Alianza.

POPPER, K. 1963. Conjectures and Refutations: The Growth of Scientific Knowledge. London: Routledge.

PRZEWORSKI, A. 1986. Capitalism and Social Democracy. Studies in Marxism and Social Theory. Cambridge (UK): Cambridge University.

SANTOS, W. G. 1985. O século de Michels: competição oligopólica, lógica autoritária e transição na América Latina. Dados, Rio de Janeiro, v. 28, n. 3, p. 283-310.

SEYD, P. \& WHITELEY, P. 1996. L'Évolution récente des adhérents du Parti conservateur et du Parti travalliste en Grande-Bretagne. Revue Française de Science Politique, Paris, v. 46, n. 6, p. 914-935. Disponível em: http:// www.persee.fr/web/revues/home/prescript/ article/rfsp 0035-2950 1996 num 46_6_395114. Acesso em: 15.out.2012.

TARDIEU, A. 1937. La Révolution à refaire. T. 2: La Profession parlementaire. Paris: Flammarion.

TSEBELIS, G. 1998. Jogos ocultos. Escolha racional no campo da política comparada. São Paulo: USP.

WEBER, M. 1984a. Economia y sociedad. Ciudad de México: Fondo de Cultura Económica.

1984b. Política como vocação. In: Ciência e política: duas vocações. São Paulo: Cultrix. 
DECADES OF MICHELS: CONTEXTUAL FRAMES AND “EXPIRATION DATES” OF THE IRON LAW

\section{André Marenco and Maria Izabel Noll}

The central argument behind this paper is that there is an "expiration date" for the effects of the iron law of oligarchies, a proposal that Robert Michels coined in his 1911 book, Political Parties. In the first section, we sketch out the social and institutional bases that served as a propitious context for turning the European socialist parties of the early twentieth century into oligarchical parties: the expansion of suffrage and the integration of candidates without property or high income into electoral competition, combining electoral reform with the substitution of majority vote for proportional representation. This was accompanied by shifting the making and organizing of candidate lists to the hands of party leadership. In the second section, we seek to provide some nuance to Robert Michels' somber prognosis on party organization, considering the factors that contribute to a greater or lesser delegation of internal power to party leaders.

KEYWORDS: Robert Michels; Iron Law of Oligarchy; Democracy; Political Parties; Party Organization. 
DES DÉCENNIES DE MICHELS: LES MARQUES CONTEXTUELLES ET LA DATE D'EXPIRATION DE LA LOI DE FER

\section{André Marenco et Maria Izabel Noll}

L'Argument central de cet article expose qu'il existe une date d'expiration temporelle pour l'effet de la loi de fer des oligarchies, une proposition faite par Robert Michels dans son oeuvre La Sociologie des partis politiques, de 1911. L'article présente, dans sa première partie, les bases sociales et institutionnelles qui ont servi comme des marques contextuelles appropriées à la conversion des partis socialistes européens au début du XX siècle dans des oligarchies partidaires: l'expansion du suffrage et l'intégration dans la compétition électorale de candidats dépourvus de propriétés et revenu, avec des réformes électorales, et le remplacement du vote majoritaire par la représentation proportionnelle, spécialement accompagnée par le transfert aux dirigeants de la prérogative de confection et ordonnance de listes de candidats partidaires. Dans la deuxième partie de l'article, on cherche à nuancer les sombres prognostiques de Robert Michels autour de l'organisation partidaire, en considérant les facteurs qui contribuent pour une plus grande ou petite délégation du pouvoir interne des partis à leurs dirigeants.

MOTS-CLÉS: Robert Michels; loi de fer des oligarchies; démocraties; partis politiques; organisation partidaire. 